Research article

\title{
Morphology and phylogeny reveal two new records of boletoid mushrooms for the Indian mycobiota
}

\author{
Dyutiparna Chakraborty ${ }^{1}$, Kamal C. Semwal ${ }^{2}$, Sinchan Adhikari ${ }^{3}$, \\ Sobhan K. Mukherjee ${ }^{3}$ and Kanad Das ${ }^{1} *$ \\ ${ }^{1}$ Cryptogamic Unit, Botanical Survey of India, P.O. Botanic Garden, Howrah-711103, India \\ ${ }^{2}$ Department of Biology, College of Sciences, Eritrea Institute of Technology, Mai Nafhi, Asmara, Eritrea \\ ${ }^{3}$ Department of Botany, University of Kalyani, Kalyani-741235, Nadia, West Bengal, India
}

*Corresponding Author: daskanadbsi@gmail.com

[Accepted: 16 February 2017]

\begin{abstract}
A detailed macro- and micromorphological studies coupled with the LSU-based phylogenetic inference of Aureoboletus nephrosporus, a tubulose member of the family Boletaceae is presented. Similarly, another tubulose bolete, Strobilomyces mirandus which was collected both from Eastern and Western Himalayas of India is also reported here with morphological details and ITS-based phylogeny. Both are the new records for this country.
\end{abstract}

Keywords: Boletales - India - Macrofungi - New records - Phylogeny - Sikkim.

[Cite as: Chakraborty D, Semwal KC, Adhikari S, Mukherjee SK \& Das K (2017) Morphology and phylogeny reveal two new records of boletoid mushrooms for the Indian mycobiota. Tropical Plant Research 4(1): 62-70]

\section{INTRODUCTION}

The members of the family Boletaceae are mostly ectomycorrhizal in tropical to subalpine regions and thus are well represented in Sikkim of the Eastern Himalaya (Lakhanpal 1996, Das 2009, 2012, 2013, Chakraborty \& Das 2015, Das \& Chakraborty 2014, Das \& Dentinger 2015, Das et al. 2012, 2013, 2014, 2015) because of the abundance of suitable host trees like Abies Mill., Picea Mill., Tsuga Carrière, Lithocarpus Blume, Castanopsis (D. Don) Spach, Quercus L., etc. and favourable microclimates. A hitherto poorly recorded (from India) ectomycorrhizal and tubuloid bolete genus Aureoboletus Pouzar is separated from the rest of the tubulose members of Boletaceae by its glutinous pileus, brightly yellow colored hymenophore which is unchanging on bruising, ixotrichodemis pileipellis (rarely trichodermis) and smooth basidiospores. In a recent macrofungal foray in 2016 to South and East districts of Sikkim, a number of boletoid mushrooms were collected by authors (DC \& KD) along with other mushroom members and after thorough morphological examination and molecular phylogenetic studies of those mushrooms, one appeared as a recently established species: Aureoboletus nephrosporus G. Wu \& Zhu L. Yang which is reported so far from China (Wu et al. 2016). It is described here for the first time from India with a detailed macro- and micromorphology along with an LSU-based phylogeny.

The representatives of another genus Strobilomyces Berk. (Boletaceae) are characterised mainly by greyish or blackish pileus, the presence of squamules or scales on pilear surface, ornamented basidiospores (Smith \& Thiers 1971, Singer 1986). They are fairly common in India and are distributed from subtropical to subalpine zones (Bilgrami et al. 1991, Lakhanpal 1996, Kour 2013, Das et al. 2014). During last couple of forays to Eastern and Western Himalayas of India from 2007 to 2016 authors (DC, KCS \& KD) came across repeatedly an interesting member of this boletoid genus. Thorough studies (morphology and ITS-based phylogeny) of the collected materials revealed a species of this genus with unusual morphology i.e. Strobilomyses mirandus Corner. A detailed macro- and micromorphology along with the ITS-based phylogeny of this species are also presented here for the first time from the country.

\section{MATERIALS AND METHODS}

Morphology

Macrofungal forays were undertaken by three of us (DC, KCS \& KD) to different parts of Eastern (South and East districts of Sikkim) and Western Himalaya during the rainy season (July-August) in 2016. 
Macromorphological characters were observed in the field and or basecamp from the fresh and dissected young to mature basidiomata. Samples were duly dried with respective field-drier. Images of these basidiomata were captured with the help of Canon Power Shot SX 220 HS and Nikon Coolpix P510. Micromorphological characters were observed with the help of a compound microscope (Nikon Eclipse $\mathrm{N} i$-U) from the dry samples mounted in a mixture of $5 \% \mathrm{KOH}, 1 \%$ Phloxin and $1 \%$ Congo red or in distilled water. Color codes and terms mentioned here are mostly after Methuen Handbook of Color (Kornerup \& Wanscher 1978). Micromorphological drawings were prepared with a drawing tube (attached to the Nikon Eclipse Ni or Olympus CX 41) at 1000×. Basidium length excludes sterigmata. Basidiospore measurements were recorded in profile view from 20 basidiospores mounted from a spore print. Spore measurements and length/width ratios (Q) are given here as minimum-mean-maximum. Methods for SEM follow Das et al. (2015). Herbarium codes follow Thiers (continuously updated).

\section{DNA extraction, polymerase chain reaction (PCR) and sequencing}

Genomic DNA (for a molecular phylogeny) was extracted from $100 \mathrm{mg}$ of dried basidiome of each of the species with the help of InstaGeneTM Matrix Genomic DNA isolation kit (Biorad, USA) following the manufacturer's instructions. The nrITS gene region was amplified with primer pairs ITS5 and ITS4 (White et al. 1990). Similarly, the nrLSU gene region was amplified with primer pairs LR0R and LR7 (http://www.biology.duke.edu/fungi/mycolab/primers.htm). PCR was performed in volumes of $25 \mu \mathrm{L}$ containing $2.5 \mu \mathrm{L}$ of $10 \mathrm{x}$ assay buffer (100 mM Tris-Cl; pH 8.3, $500 \mathrm{mM} \mathrm{KCl,} 15 \mathrm{mM} \mathrm{MgCl}$ ), $200 \mu \mathrm{M} \mathrm{dNTP}$ mix (Bangalore Genei, Bangalore, India), 10 picomoles of primer, 1.0 unit of Taq DNA polymerase (Bangalore Genei), and $30 \mathrm{ng}$ of template DNA. Then PCR-amplification was done with a thermal cycler (Eppendorf, Germany) programmed for $2 \mathrm{~min}$ at $94^{\circ} \mathrm{C}$, followed by 35 cycles of $45 \mathrm{sec}$ at $94^{\circ} \mathrm{C}, 1 \mathrm{~min}$ at $55^{\circ} \mathrm{C}, 1 \mathrm{~min}$ at $72^{\circ} \mathrm{C}$ and a final stage of $10 \mathrm{~min}$ at $72^{\circ} \mathrm{C}$ for ITS region. The PCR condition for nLSU was as follows: 5 min at $95^{\circ} \mathrm{C}$, followed by 30 cycles of $1 \mathrm{~min}$ at $95^{\circ} \mathrm{C}, 30 \mathrm{~s}$ at $52^{\circ} \mathrm{C}$ (for D1D2 region), 2 min at $72^{\circ} \mathrm{C}$ and a final 7 min extension step at $72^{\circ} \mathrm{C}$. The PCR products were purified using the QIAquick PCR Purification Kit (QIAGEN, Germany). Both strands of the PCR fragment were sequenced on the 3730xl DNA Analyzer (Applied Biosystems, USA) using the amplifying primers. The DNA sequence of the reverse strand was edited with Sequence Navigator version 1.0.1 (Applied Biosystems). The final consensus sequences were deposited at GenBank to procure the accession numbers (KY412776 for LSU of Aureoboletus nephrosporus and KY412777 for ITS of Strobilomyces mirandus).

\section{Phylogenetic analysis}

Phylogenetic analyses based on ITS and LSU sequences data were carried out to establish the phylogenetic placement of our isolated taxa. Reference sequences and outgroups were selected from the relevant literature and GenBank. Alignment were performed using CLUSTAL W (http://www.ebi.ac.uk/clustalw/) and phylogenetic analyses were conducted in MEGA 6.0 (Tamura et al. 2013). No manual editing was done within the alignment. The evolutionary history was inferred by using the Maximum Likelihood method based on the Kimura 2-parameter model (Kimura 1980). One thousand bootstrap replicates were analysed to obtain nodal support values. The European material of Boletus edulis was chosen as out group taxon in our ITS-based analysis whereas, Phylloporus rhodoxanthus (North American sample) and Xerocomus subtomentosus (European sample) were chosen as outgroups in our LSU-based analysis.

\section{RESULTS}

Phylogeny

Our LSU-based phylogenetic analysis (Fig. 1) with 22 LSU sequences (including the present species) resolved genus Aureoboletus with full support. The sequence (GenBank accession no. KY412776) derived from Indian collection of Aureoboletus nephrosporus G. Wu \& Zhu L. Yang is clustered with the sequences derived from its Chinese counterpart (represented by GenBank accession numbers KT990516 and KT990517) showing the conspecificity (100\% identity in BLAST search) with strong support (BS value). Similarly, our ITS based phylogeny (Fig. 2) clearly supports the existence of two distinct clades (Clade A and Clade B) in the genus Strobilomyces which are also reported by the earlier workers like, Gelardi et al. (2012) and Antonin et al. (2015). Clade A includes Strobilomyces confusus Singer, Strobilomyces seminudus Hongo, Strobilomyces verruculosus Hirot. Sato where basidiospores are never with reticulation. Distinguishingly, Clade B represented by Strobilomyces strobilaceous (Scop.: Fr) Berk., Strobilomyces sp. (from India), S. echinocephalus Gelardi \& 
Chakraborty et al. (2017) 4(1): 62-70

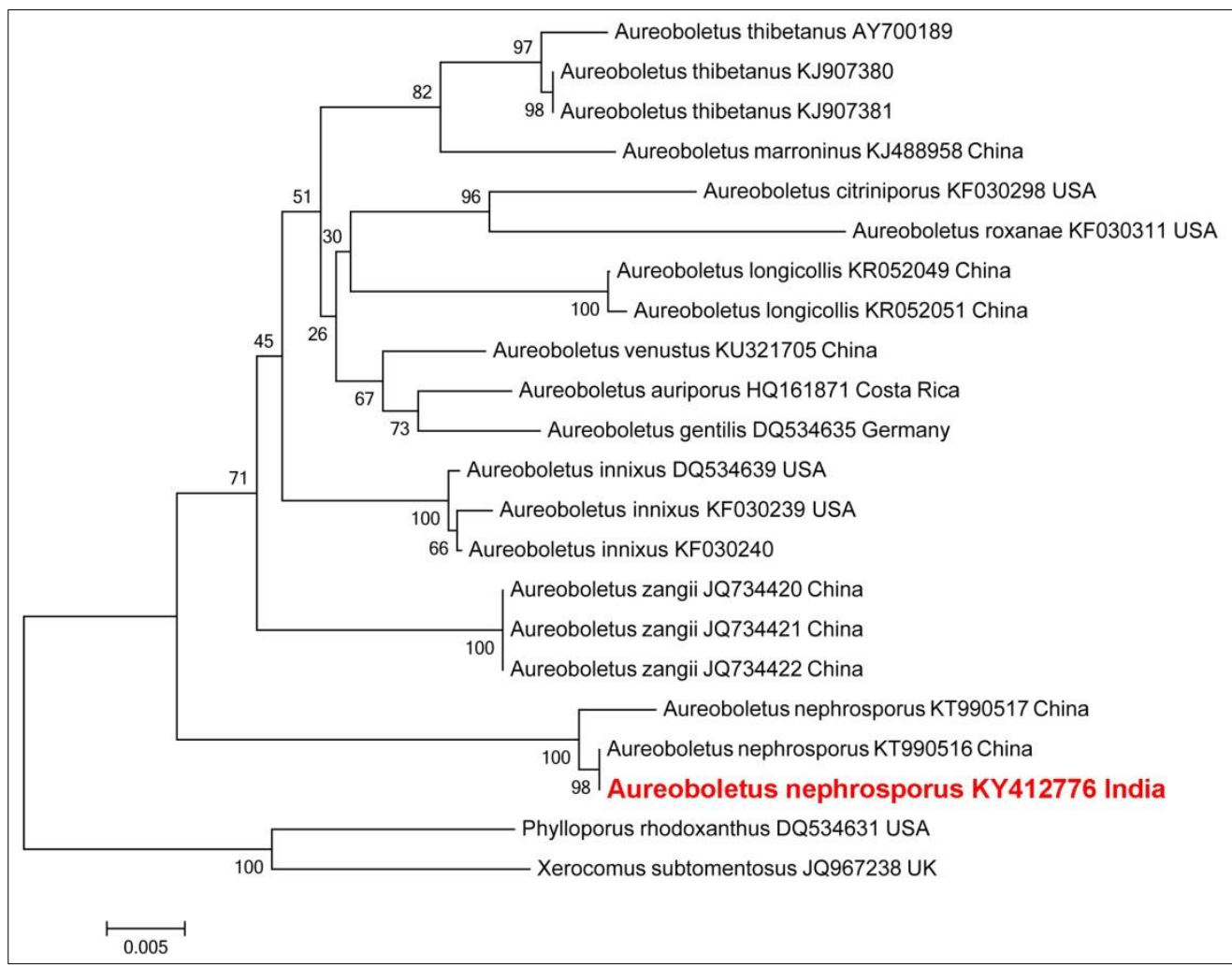

Figure 1. Phylogram of DC 16-29 (Aureoboletus nephrosporus G. Wu \& Zhu L. Yang, in bold and red font) inferred from Maximum Likelihood analysis of nrLSU sequences using MEGA 6.0.

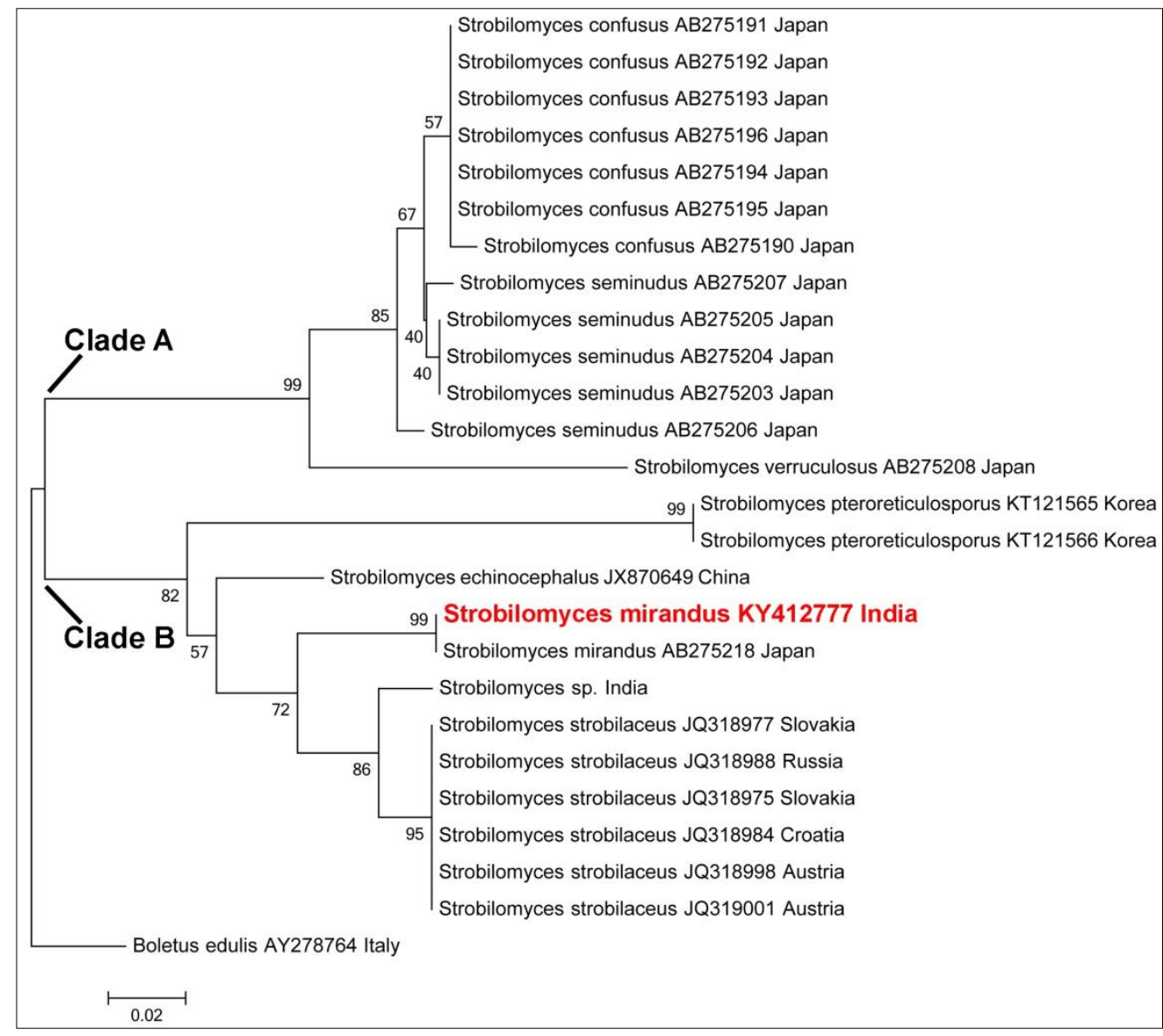

Figure 2. Phylogram of DC 16-27 (Strobilomyces mirandus Corner, in bold and red font) inferred from Maximum Likelihood analysis of nrITS sequences using MEGA 6.0. 
Vizzini., S. pteroreticulosporus Antonín \& Vizzini, S. mirandus where basidiospores are typically reticulate (Gelardi et al. 2012, Antonin et al. 2015). The sequence (GenBank accession no. KY412777) from our present Indian material of Strobilomyces (DC 16-27) showing conspecificity (99\% identity in BLAST search) is clustered with the sequence derived from S. mirandus from Japan with strong support (bootstrap value 99).

\section{Taxonomy}

Aureoboletus nephrosporus G. Wu \& Zhu L. Yang, Fungal Diversity, DOI 10.1007/s13225-016-0375-8

(Figs. 3 \& 4)

Pileus 45-70 mm diam, subhemispherical to convex, sometimes with a broad umbo when young; surface mat, subvelvety, reddish brown (8D6) or brownish red to greyish red (10D6-5) when dry, turning dark brown $(8 \mathrm{~F} 8)$ with $\mathrm{KOH}$ and greenish grey (26E2) with $\mathrm{FeSO}_{4}$; margin with sterile flap of tissue. Pore surface yellow (2A8), becoming dingy with time, unchanging when bruised; pores 0.7 per $\mathrm{mm}$ in mature basidiomata, rounded to angular, compound. Tubes up to $50 \mathrm{~mm}$ long, subdecurrent to decurrent, light yellow (2A5). Stipe 90-170 $\times$ 7-15 mm, central, cylindrical, tapering at base; surface covered with striations; light yellow (5A6) to yellow ochre (5C7), olive (3E3) or greenish black when bruised. Context pale yellow (3A3) at pileus, turning golden yellow (5B7) with $\mathrm{KOH}$; pastel yellow (3A4) or darker at stipe, turning reddish brown (8D8) with $\mathrm{KOH}$.
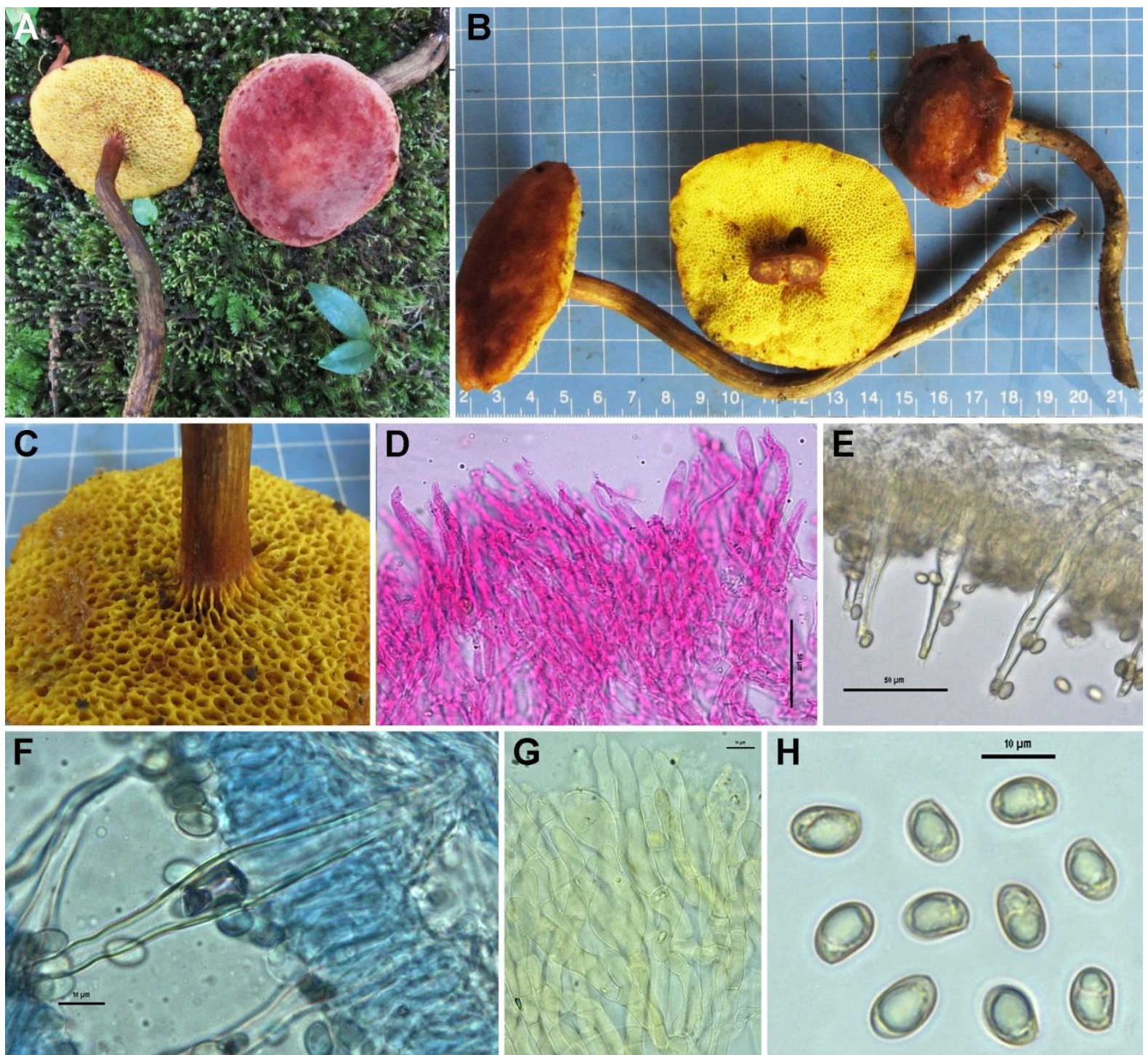

Figure 3. Aureoboletus nephrosporus G. Wu \& Zhu L. Yang: A \& B, Young and mature fresh basidiomata in field; C, Pore surface; D, Pileipellis; E \& F, Pleurocystidia; G, Caulocystidia; H, Basidiospores. Bars. [Scale: D-E, $50 \mu \mathrm{m} ; \mathbf{F}-\mathbf{H}, 10 \mu \mathrm{m}$ ]

Basidiospores 8.5-9.5(-10.8) × 5.6-6.2(-6.7) $\mu \mathrm{m},(\mathrm{Q}=1.41-1.53(-1.71))$, ovoid to ellipsoid or nephroid, inequilateral, smooth under a light microscope. Basidia 37-55 × 10-13 $\mu \mathrm{m}, 4$-spored, clavate. Pleurocystidia 50-70 $\times 9-13 \mu \mathrm{m}$, emergent up to $60 \mu \mathrm{m}$, fusoid to ventricose, mostly with thick covering, rarely thin walled. 
Subhymenial layer up to $25 \mu \mathrm{m}$ thick, hyphal. Tube edge fertile with basidia and cystidia. Hymenophoral trama mostly parallel to subparallel or sometimes interwoven. Pileipellis a trichodermis, up to $200 \mu \mathrm{m}$ thick, composed of erect hyphae of slightly inflated cells; terminal cells $23-44 \times 7.2-10 \mu \mathrm{m}$, cylindrical to subcylindrical, sometimes subfusoid. Stipitipellis up to $160 \mu \mathrm{m}$ thick, composed of hyphae and cystidia in several clusters; basidia not observed; caulocystidia 40-55 × 8-20 $\mu \mathrm{m}$, broadly ventricose to lanceolate, clavate to subclavate or cylindrical with fusoid apex.

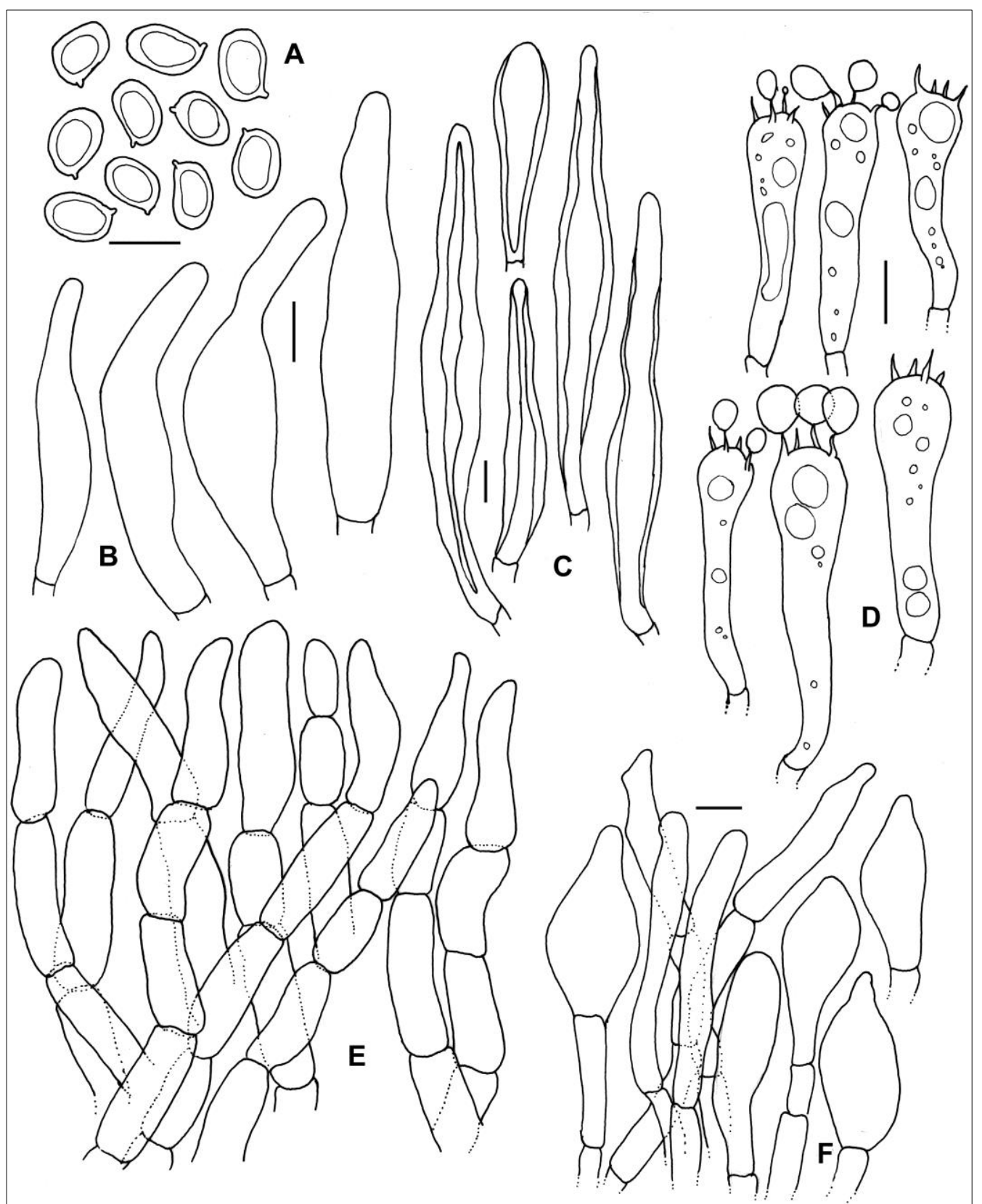

Figure 4. Aureoboletus nephrosporus G. Wu \& Zhu L. Yang: A, Basidiospore; B, Pleurocystidia without covering of refractive substance; C, Pleurocystidia with covering of refractive substance; D, Basidia; E, Pileipellis; F, Caulocystidia. [Scale: A-F, $10 \mu \mathrm{m}$ ]

Distribution: China and India (Sikkim).

Specimen examined: India, Sikkim, South district, Maenum Wild life Sanctuary (Maenum top 2), $2315 \mathrm{~m}$, N27²19'18.7" E88²2’07.9", under Quercus sp., $21^{\text {st }}$ August 2016, D. Chakraborty \& K. Das, DC 16-29 (CAL).

Note: The combination of macro- and micromorphological characters like fleshy tubulose basidiomata with reddish, dry or mat pilear surface, bright yellow pore surface, unchanging (on bruising) context color and smooth nephroid basidiospores place the Indian collection under the genus Aureoboletus. Further, A. nephrosporus is micromorphologically distinct from rest of the species of this genus by the presence of nephroid www.tropicalplantresearch.com 
basidiospores and surface of pleurocystidia being covered with a thick layer of a strongly refractive substance which is often dissolved in $\mathrm{KOH}$ (Wu et al. 2016). Morphology of the Indian material [except the stipe (which is longer) and pleurocystidia (which is smaller)] is mostly in conformity with that of its counterpart from China. Moreover, our LSU-based phylogeny strongly shows the conspecificity of our collection to Aureoboletus nephrosporus (represented by KT990516 in Fig. 1), the Chinese counterpart both in morphology and phylogeny. But, the Chinese material shows somewhat different altitudinal variation (collected from subtropical belt: 1700 m). Another Chinese species, Aureoboletus zangii X.F. Shi \& P.G. Liu (represented by JQ734420 to JQ734422 in Fig. 1) is quite similar to A. nephrosporus, however, the former differs by its viscid pileus and stipe, fox red or English red colored stipe-surface and narrower basidiospores $(3-4 \mu \mathrm{m})(\mathrm{Wu}$ et al. 2016) from the latter. Aureoboletus thibetanus (Pat.) Hongo \& Nagas. (the only other species from this genus reported from India) can easily separated from A. nephrosporus by presence of strongly reticulate and highly glutinous pileus surface (Sharma et al. 2005).

Strobilomyces mirandus Corner, Boletus in Malaysia: 61 (1972).

(Figs. 5, 6)

Pileus 37-75 mm. diam.; convex, vivid yellow to sunflower yellow (3A8-4A7); surface densely squamulose with flat to bluntly pyramidal or wart-like squamules, which are more dense towards centre, brown (7E-F4) to blackish brown, surface brownish red (8-9C8) with $\mathrm{KOH}$; margin wavy with cottony veiler remnant, vivid yellow (3A8). Pore surface covered by partial veil when young, smoky white; depressed near stipe, brownish initially then blackish on bruising; pore $2 / \mathrm{mm}$, simple, angular. Tube $12-16 \mathrm{~mm}$ long, adnate-sinuate, chalky to smoky white, then greyish brown (7D3). Stipe 55-90 × 17-28 mm, central, concolorous with pileus, with the cotton-like annular region; surface with reticulations on the upper portion of the annular region, striations with pit like openings throughout the rest; basal mycelium greyish magenta (13B3). Context solid in pileus and stipe; context in pileus chalky white but immediately turning greyish orange (7C4) and then brownish grey (7E2) or brownish black on exposure, turning reddish orange to brownish orange (7B-C8) with $\mathrm{KOH}$, greenish grey to dull green (26B2-26D3) with $\mathrm{FeSO}_{4}$ in pileus, stipe context chalky white turning dark brown to brownish black with an intermediate orange brown to red brown coloration when exposed. Spore print blackish brown. Taste indistinct. Odour indistinct.

Basidiospores 7.2-8.8(-10.5) $\times$ 6-6.9(-7.7) $\mu \mathrm{m},(\mathrm{Q}=1.09-1.26(-1.45))$, mostly subglobose or broadly ellipsoid, ornamented, forming complete reticulation. Basidia 38-48 $\times 10-16 \mu \mathrm{m}$, four-spored, clavate. Pleurocystidia 60-90 × 15-20 $\mu \mathrm{m}$, fusoid to ventricose or ventricose rostrate, brown pigmented. Hymenophoral trama divergent. Pileipellis a trichodermis, 200-400 $\mu \mathrm{m}$ thick, composed of erect to suberect hyphae of slightly inflated to elongated cells, with minute incrustations; terminal cells $22-75 \times 8-112 \mu \mathrm{m}$, cylindrical to subcylindrical. Stipitipellis hyphal, same as pileal hyphae; cystidia in several clusters; basidia not observed; caulocystidia $32-53 \times 01-13 \mu \mathrm{m}$, broadly ventricose to lanceolate, clavate to fusoid.

Distribution: Malaysia, Japan, China and India (Sikkim).

Specimens examined: India, Sikkim, South district, Rabangla, 1985 m, N27 $15^{\prime} 14.8^{\prime \prime}$ E88 23'03.7', under Lithocarpus sp., $20^{\text {th }}$ August 2016, D. Chakraborty \& K. Das, DC 16-27; ibid., South district, Kewzing, 1888 m, N27 $17^{\prime} 46.5^{\prime \prime}$ E88 $21^{\prime} 26.6^{\prime \prime}$, under Lithocarpus sp., $21^{\text {st }}$ August 2016, D. Chakraborty \& K. Das DC 16-028 (CAL); Uttarakhand, Rudraprayag, Kund, $1160 \mathrm{~m}$, under Cinnamomum tamala and Quercus glauca, $13^{\text {th }}$ August 2007, K.C. Semwal, KCS 1102; $12^{\text {th }}$ August 2016, K.C. Semwal, KCS 2556.

Note: Unlike other (Asian or extralimital) species of Strobilomyces, present one i.e. S. mirandus has entirely distinct combination of macromorphological features like golden yellow to yellowish orange or yellow colored pileus (distinct from any known species of this genus) with blackish brown squamules, pileus margin with yellow veilar remnants, smoky white pore surface (turning brownish after bruising), yellow stipe with cottony annular region. Morphological features of Indian collection is on conformity to its counterparts reported from other Asian countries like Malaysia, Japan or China (Corner 1972, Sato et al. 2005, Ge \&Yang 2005) and the combination of our ITS-based phylogeny and morphological studies further warrants its wider range of distribution in different countries of Asia. Moreover, the occurrence of S. mirandus strengthens the representation of this genus in India with eight species (Strobilomyces strobilaceus (Scop.) Berk., S. nigricans Berk., S. polypyramis Hook. f., S. velutipes Cooke \& Massee, S. annulatus Corner, S. mollis Corner, S. mirandus Corner and Strobilomyces sp. (unpublished and represented by "Strobilomyces sp." in our ITS-based tree: Fig. 2). 

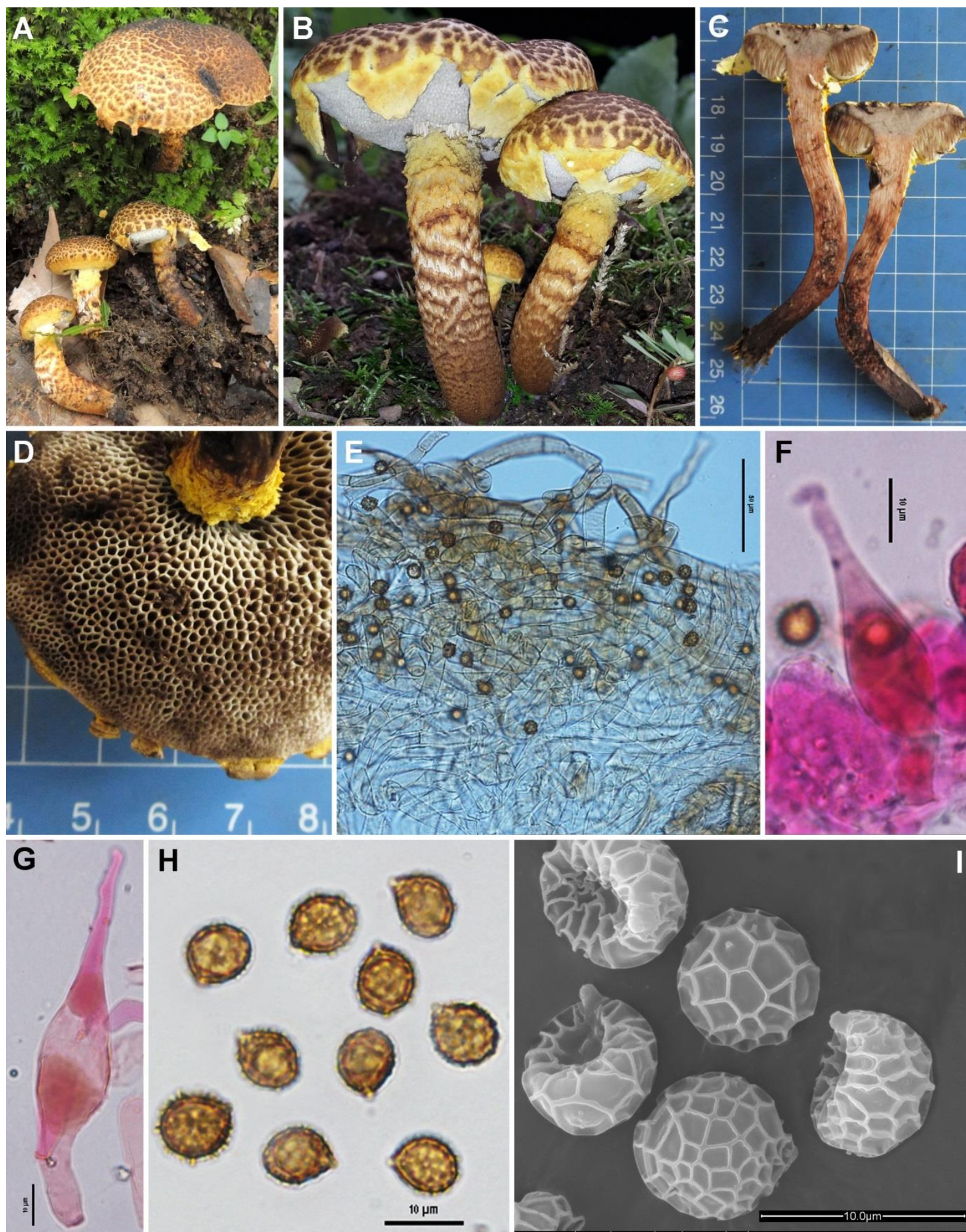

Figure 5. Strobilomyces mirandus Corner: A-C, Young and mature fresh basidiomata in field and in basecamp; D, Pore surface; E, Pileipellis; F-G, Pleurocystidia; H, Basidiospores; I, SEM of basidiospores. [Scale: E, $50 \mu \mathrm{m} ; \mathbf{F}-\mathbf{I}, 10 \mu \mathrm{m}$ ]

In the western Himalaya, S. mirandus was collected from the present locality (Kund Forest) very first time in 2007. That time the forest was so fruitful with abundant suitable hosts, leaf litter and humus and about 25 mushroom species had been encountered in a small area in a day on August 13, 2007, but in the year of 2016 when the forest area has been visited again on August, 12, it was observed that the forest trees were so less with very less leaf litter and humus. Only 3 wild mushrooms species has been encountered. So from August 2007 to August 2016 several factors dramatically altered the scenario of the concerned forest. It has been assumed that the several anthropogenic activities (construction of hydropower dam and subsequent shifting of the respective 
national highway) which developed in recent years are the cause of the declination of the mushroom diversity in this area. Moreover, the host trees are likely to be cut shortly in order to shift the national highway. Therefore, we are afraid that there will be the declination of $S$. mirandus from Western Himalaya of India once all these ongoing construction activities will be over.

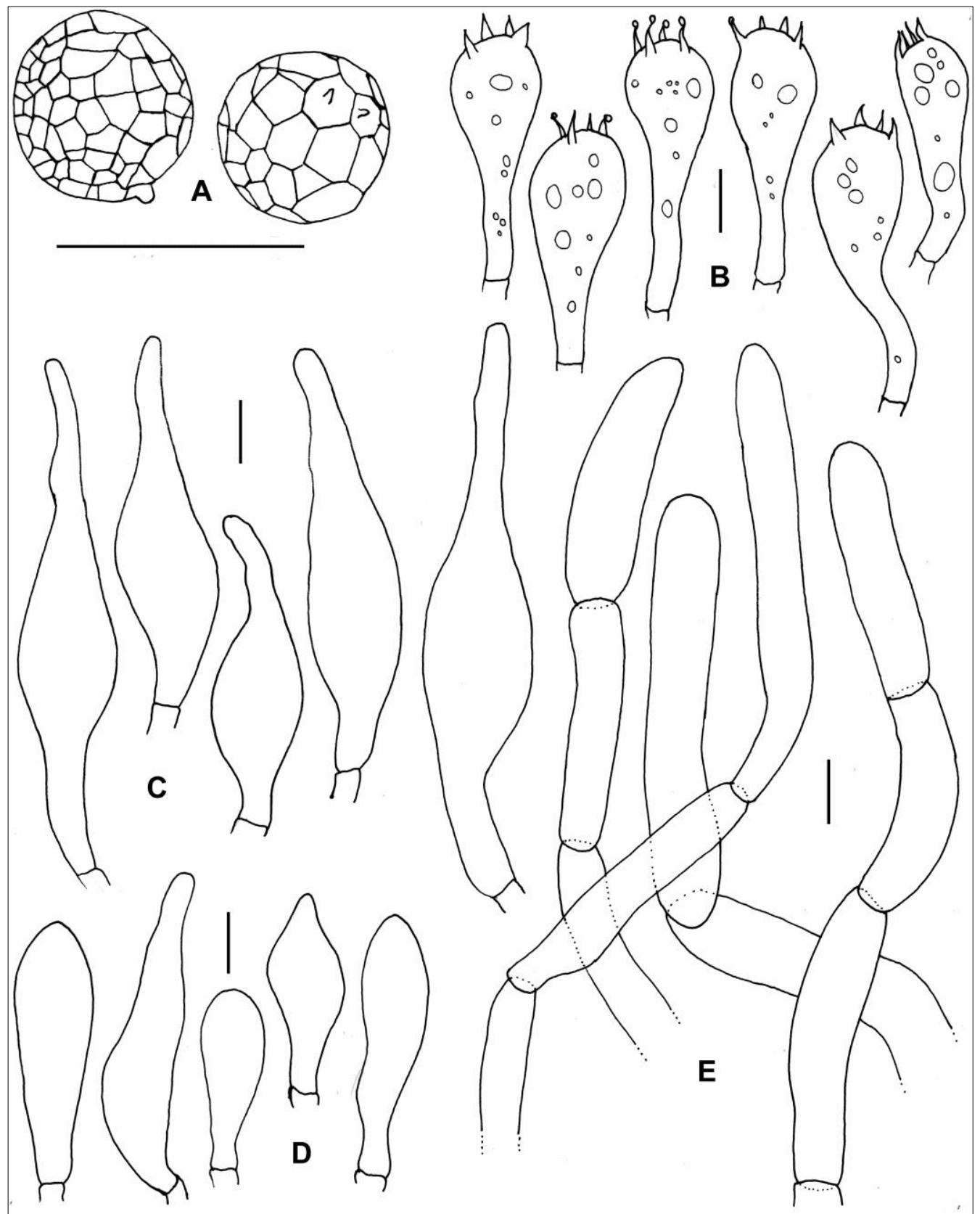

Figure 6. Strobilomyces mirandus Corner: A, Basidiospore; B, Basidia; C, Pleurocystidia; D, Caulocystidia; E, Pileipellis. [Scale: A-E, $10 \mu \mathrm{m}$ ]

\section{ACKNOWLEDGEMENTS}

The authors are grateful to the Director, Botanical Survey of India (Kolkata) and the Scientist-in-Charge, Botanical Survey of India (Gangtok) for providing facilities. DC \& KD are thankful to the entire forest department of Sikkim for allowing us (KD \& DC) to undertake the macrofungal surveys to the restricted areas of South district of Sikkim. Assistance (to KD \& DC) rendered by Subhash Pradhan (BSI, Gangtok) in the field is duly acknowledged.

\section{REFERENCES}

Bessette AE, Roody WC \& Bessette AR (2010) North American Boletes: a color guide to the fleshy pored mushrooms. Syracuse University Press, New York. 
Bilgrami KS, Jamaluddin S \& Rizwi AM (1979) Fungi of India. Part-I: Lists and References. Today and Tomorrow's Printers and Publishers, New Delhi.

Chakraborty D \& Das K (2015) A new generic record of Boletaceae for Indian mycobiota. Current Research in Environmental \& Applied Mycology 5(2): 138-144.

Corner EJH (1972) Boletus in Malaysia. Government Printing Office, Singapore.

Das K \& Chakraborty D (2014) Boletus sharmae, a new species from Sikkim (India). Indian Journal of Plant Sciences 3 (1): 19-24.

Das K \& Dentinger BTM (2015) Austroboletus olivaceoglutinosus, a new mushroom species from Sikkim, India with a distinctive green, glutinous pileus. Kew Bull 70: 15.

Das K (2009) Mushrooms of Sikkim I: Barsey Rhododendron Sanctuary. Sikkim State Biodiversity Board, Department of Forest, Environment \& Wildlife Management, Gangtok \& Botanical Survey of India, Ministry of Environment and Forests, Govt. of India, Kolkata.

Das K (2012) New distributional record of Retiboletus ornatipes (Peck) Binder \& Bresinsky (Boletaceae) from North and West districts of Sikkim. Indian Journal of Plant Sciences 2(1): 1-5.

Das K (2013) Boletus rubripes Thiers, a new record of wild mushroom from Sikkim (India). Taiwania 58 (2): 136-139.

Das K, Chakraborty D, Baghela A, Singh SK \& Dentinger BTM (2014) Boletus lakhanpalii, a new species in Boletaceae from Sikkim (India) with uncertain phylogenetic placement. Sydowia 67: 11-19.

Das K, Hembrom ME, Parihar A, Mishra D \& Sharma JR (2014) Strobilomyces polypyramis - rediscovery of a wild mushroom from Sikkim, India. Indian Journal of Plant Sciences 3(2): 13-18.

Ge ZW \& Yang ZL (2005) Strobilomyces mirandus a species new to China. Mycocystema 24(1): 143-144.

Kornerup A \& Wanscher JH (1978) Methuen handbook of color, $3^{\text {rd }}$ Edition. Eyre Methuen Ltd., U.K.

Kour H, Kumar S \& Sharma YP (2013) Two species of Strobilomyces from Jammu and Kashmir, India. Mycosphere 4(5): 1006-1013.

Lakhanpal TN (1996) Mushrooms of India: Boletaceae, volume I. APH Publishing Corporation, New Delhi, India.

Manjula B (1983) A revised list of agaricoid and boletoid basidiomycetes from India and Nepal. Proceedings of the Indian Academy of Sciences Plant Science 92: 81-213.

Sato H, Hattori T, Kurogi S \& Yumoto T (2005) Strobilomyces mirandus Corner, a new record from Japan. Mycoscience 46: 102-105.

Sharma JR, Das K \& Kukreti S (2005) Two new records of fleshy fungi from India. Indian Journal of Forestry 28(1): 78-80.

Singer R (1986) The Agaricales in modern taxonomy, $4^{\text {th }}$ Edition. Koeltz. Scientific Books, Koenigstein.

Smith AH \& Thiers HD (1971) The Boletes of Michigan. University of Michigan Press, Ann Arbor, USA.

Thiers B [continuously updated] Index Herbariorum: A global directory of public herbaria and associated staff. New York Botanical Garden's Virtual Herbarium. Available from: http://sweetgum.nybg.org/science/ih/ (accessed: 12 Oct. 2016).

Wu G, Li YC, Zhu XT, Zhao K, Han LH, Cui YY, Li F, Xu JP \& Yang ZL (2016) One hundred noteworthy boletes from China. Fungal Diversity 81(1): 25-188. 